ACADEMIA ROMÂNĂ Roum. Chim.,
Revue Roumaine de Chimie
http://web.icf.ro/rrch/

\title{
THEORETICAL STUDY OF BIS-ADDUCT FULLEROPYRROLIDINES ISOMERS
}

\author{
Seif BENNIA, ${ }^{\mathrm{a}, \mathrm{b}}$ Noura KHEMIRI, ${ }^{\mathrm{a}, \mathrm{c}}$ Rim MILAD, ${ }^{\mathrm{a}}$ Abdesslem JEDIDI, ${ }^{\mathrm{d}}$ Manef ABDERRABBA, ${ }^{\mathrm{a}}$ \\ and Sabri MESSAOUDI ${ }^{\mathrm{a}, \mathrm{b}, \mathrm{e}^{*}}$ \\ ${ }^{a}$ Laboratoire Matériaux, Molécules et Applications, Institut Préparatoire aux Etudes Scientifiques et Techniques, La Marsa, \\ Université de Carthage, Carthage, Tunisia \\ ${ }^{\mathrm{b}}$ Faculté des sciences de Bizerte, Université de Carthage, Carthage, Tunisia \\ ${ }^{\mathrm{c}}$ Physics department, Science Faculty at Yanbu, Taibah University, Yanbu, Madina, Saudi Arabia \\ ${ }^{\mathrm{d}}$ Chemistry Department, Faculty of Science, King Abdulaziz University, Jeddah 21589, Saudi Arabia \\ ${ }^{\mathrm{e}}$ Department of Chemistry, College of Science, Qassim University, Buraydah Al-Mulida, P.O. Box 6644, Buraydah 51452, Saudi Arabia
}

Received August 2018

\begin{abstract}
A detailed theoretical investigation of bis-adduct fulleropyrrolidines was developed in our work. All the possible isomers of our molecule were determined. Corresponding structures were optimized, their energies were calculated and their stability was discussed using the density functional theory method. The theoretical calculation carried out in our work shows that the trans and equatorial structures of the bis adduct are the most stable structures among the eight different possible isomers. The LUMO energy calculated for the bis adduct shows that it is higher than the LUMO of C60 and the LUMO of the mono adduct calculated at the same level. This suggests that this compound can be used efficiently as electron acceptor in photovoltaic cell application.
\end{abstract}

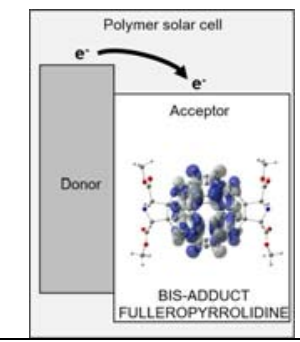

\section{INTRODUCTION}

Since their discovery in 1985 by Kroto et al., ${ }^{1}$ Fullerenes and their derivatives have interested scientists and demonstrated the importance of their use in various fields such as biomedicine, inorganic sciences and in particular renewable energies and generating electricity from photovoltaic cells. ${ }^{2}$ Thus, synthesis and characterization of novel fullerenes and their derivatives are very important for advancing fundamental knowledge towards developing next generation organic solar cells. ${ }^{3}$ These fullerene derivatives have important potential for biological applications too. ${ }^{4}$ Since Fullerenes have thirty reactive $[\mathrm{C}, \mathrm{C}]$ double bonds, poly-addition on $\mathrm{C}_{60}$ gives birth to a large number of products. ${ }^{5-7}$ Particularly, fulleropyrrolidines synthesis leads generally to a complicate mixture of several adducts in their different isomers. ${ }^{8-10}$

\footnotetext{
* Corresponding author: sabri_messaoudi@yahoo.fr
}

Compared to classic semiconductors, however, the bi functionalization of fullerenes has highlighted the crucial role that allotropic forms of carbon could play in optimizing photovoltaic cell efficiency. ${ }^{2}$ This is due to the various isomers that a bi-addition (8 isomers) could generate. These bi adducts are promising electron acceptors because of their ability to increase the open circuit voltage of the polymers of solar cells thanks to their high LUMO. Other previous researchers have shown that these various isomers have several energy levels; and the best energetic performance has been attributed to individually isolated isomers compared to the mixture of bi adducts isomers. ${ }^{2}$ This leads us to focus our study on isomers separately.

Isomers separation is not experimentally handy; we usually need a time-consuming intensive HPLC separation. There is a great difficulty to obtain pure 
isolated bis-adducts ${ }^{11}$ and therefore, poly-adduct are much more difficult to isolate. Some experimentalists have succeeded to isolate some bis-adduct isomers (Prato, NCBA, Azomethine, etc.). ${ }^{2,4,11}$

Different numbers of adducts of photo-addition of glycine methyl-ester to ${ }^{6}$ fullerene were synthesized. $^{5}$ Among the synthesized structures we find the bis adduct but to our knowledge this structure was not separated from the compounds with other number of adducts. Thus, a theoretical investigation is really needed to have a preliminary overview at this complicate mixture and facilitate its identification.

We performed, in this work, a theoretical calculation on the different possible isomers of bisadduct fulleropyrrolidines proving the existence of each one of them by use of density functional theory (DFT). We chose B3LYP functional as the most known used one ${ }^{12,13}$ and SVP, ${ }^{14} 6-31 \mathrm{G}(\mathrm{d}),{ }^{10}$ and $6-31++G(d, p)$ basis sets. We determined the most stable isomer of the studied molecule through geometry optimization and calculated several properties such as LUMO, HOMO and energy gap.

\section{Computational details}

The different isomer structures of Fulleropyrrolidines bis-adduct were optimized using DFT method with the B3LYP functiona ${ }^{13}$ in connection with a split-valence basis set (SVP keyword in Gaussian) on all the atoms as implemented in Gaussian 09 software. ${ }^{15}$ No symmetry constraints were used in the geometry optimizations, and the final geometries were confirmed to be minimum potential energy structures through frequency calculations. All systems were treated with the spin-restricted formalism. Equilibrium energies, structural and vibrational properties were calculated using density functional theory $\mathrm{DFT}^{16}$ with its B3LYP ${ }^{13}$ functional and using 6-31G(d) basis set on SVP optimized structures: B3LYP/6$31 \mathrm{G}(\mathrm{d}) / / \mathrm{SVP} .{ }^{14}$ In order to have results with more precision, we performed a purely DFT investigation on the structures having the lowest energies; i.e. the most stable isomers with the former method were optimized using B3LYP/6$31++\mathrm{G}(\mathrm{d}, \mathrm{p})$ method as implemented in Gaussian 09 software.

The UV-Vis parameters (maximum wavelength, electronic excitation energies and oscillator strengths) of the studied compounds have been calculated at the TD-B3LYP/6-31G(d) level of theory. ${ }^{17,18}$ For the comparison with $\mathrm{C}_{60}$ and the mono-adduct, we used B3LYP/6-31++G(d,p) to determine the HOMO, LUMO and the energy gap for these systems.

\section{RESULTS AND DISCUSSION}

We firstly present the studied molecule which is the bis-adduct fulleropyrrolidines. Figure 1 shows the different possible positions of the second added molecule (dimethyl 2,2'-azanediyldiacetate) regarding the first one. Eight positions are possible as described by the Hirsch nomenclature. ${ }^{19}$
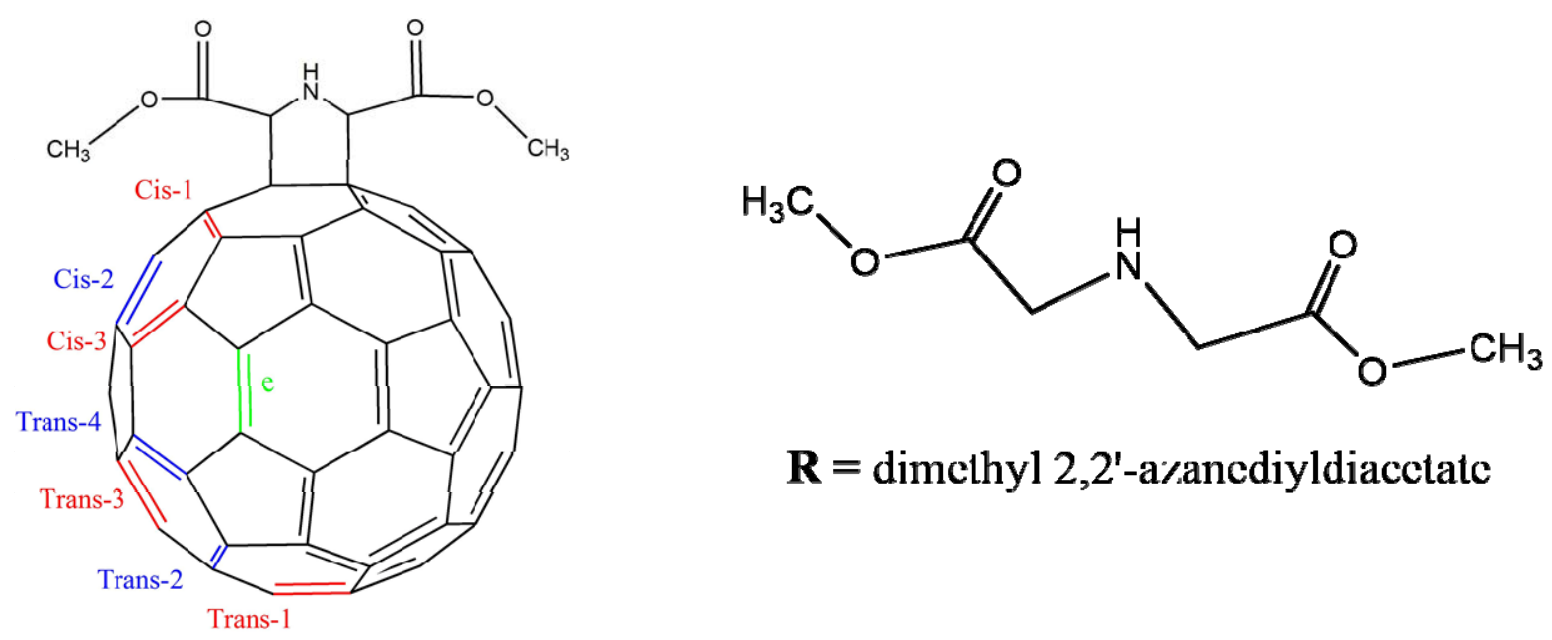

$\mathbf{R}=$ dimethyl 2,2'-azanediyldiacetatc

Fig. 1 - Hirsch nomenclature of the eight different double bonds in a $\mathrm{C}_{60}$ where a second adduct $(\mathrm{R})$ can be added relative to the $\mathrm{C}=\mathrm{C}$ bond carrying the first added adduct $(\mathrm{R})$. 
Table 1

Isomer equilibrium energies calculated by B3LYP/SVP, B3LYP/SVP//6-31G(d) and B3LYP/6-31++G(d,p) levels

\begin{tabular}{c|c|c|c|c}
\hline \multirow{2}{*}{$\#$} & \multirow{2}{*}{ Isomer } & B3LYP/SVP & B3LYP/SVP//6-31G(d) & B3LYP/6-31++G(d,p) \\
\cline { 3 - 5 } & & \multicolumn{3}{|c}{$\Delta \mathrm{E}(\mathrm{kJ} / \mathrm{mol})$} \\
\hline 1 & Cis-1 & 215.33 & 215.71 & - \\
2 & Cis-2 & 74.24 & 76.29 & - \\
3 & Cis-3 & 11.81 & 12.56 & 0.04 \\
4 & Equa & 0.15 & 0.00 & 4.24 \\
5 & Trans-1 & 3.76 & 3.96 & 2.33 \\
6 & Trans-2 & 1.90 & 2.11 & 0.00 \\
7 & Trans-3 & 0.00 & 0.05 & 4.50 \\
8 & Trans-4 & 4.39 & 4.37 & \\
\hline
\end{tabular}

Relative energies are calculated with the most stable isomer as reference.

Observing the Fig. 1, we note the existence of eight isomers. Cis-1 isomer corresponds to the structure where both adducts are linked to the same ring while Trans-1 isomer corresponds to the most spaced structure, the symmetrical one. There are four Trans isomers, three cis isomers and one equatorial isomer $(E q u a)$. All these structures are theoretically studied using DFT method. In Table 1, we summarize the energies of the different isomers calculated with SVP basis set for optimized structures then $6-31 \mathrm{G}(\mathrm{d})$ as a single point. The most stable structure energy is taken as reference. For more accuracy, selected structures have been calculated with B3LYP/6-31++G(d,p) to confirm the order of stability.

We note that the most stable structure corresponds to Trans-3 isomer then Equatorial using SVP basis set with a difference of $0.15 \mathrm{~kJ} / \mathrm{mol}$. However, Equatorial isomer Equa (see Fig. 2) becomes closer to Trans-3 when using larger basis set i.e. $6-31 \mathrm{G}(\mathrm{d})$ with a very slight difference $0.05 \mathrm{~kJ} / \mathrm{mol}$ and even a smaller difference when using larger basis set $(0.04 \mathrm{~kJ} / \mathrm{mol}$ for $6-31++\mathrm{G}(\mathrm{d}, \mathrm{p}))$.

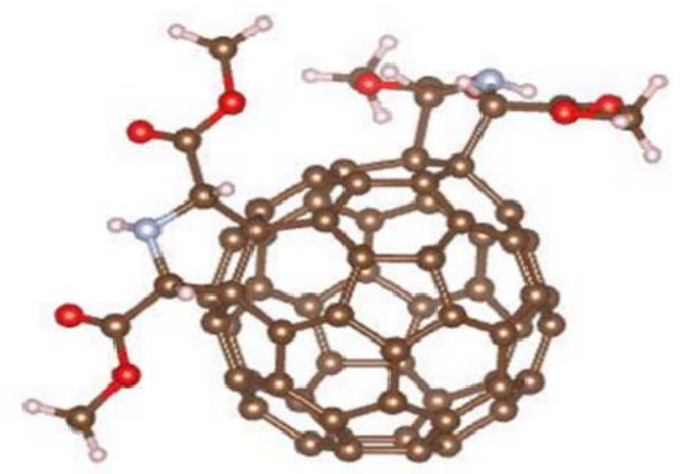

Fig. 2 - Geometry of the Equatorial isomer optimized B3LYP/6-31++G(d,p).
For B3LYP/SVP//6-31G(d), the third nearest energy corresponds to the Trans-2 isomer structure $(\Delta \mathrm{E}=2.11 \mathrm{~kJ} / \mathrm{mol})$. The symmetrical structure corresponding to Trans- 1 isomer is at about (3.96 $\mathrm{kJ} / \mathrm{mol}$ ) from the most stable one. It has a close but higher energy. This is not expected since the steric effect recommend that Trans- 1 isomer have the most stable structure.

In order to better show the stability order of the different isomers of bis-adduct fulleropyrrolidines, we plotted them according to their corresponding DFT energies in Fig. 4. We excluded from the plot the cis-isomers as they present relatively high energies.

Observing Fig. 4, we note that the Equatorial and Trans-3 are more stable than cis and others transisomers. This fact could be explained by the steric effect and by symmetry reasons. In fact, trans isomers are more spaced than cis isomers. We note also that, the least stable cis isomer is at about 215.71 $\mathrm{kJ} / \mathrm{mol}$ of energy higher than the most stable one.

According to Fig. 4, the different isomers can be ordered according to their order of stability: Equatorial, Trans-3, Trans-2, Trans-1 and Trans-4. All the latter isomers (including at some point the cis3 isomer too) can be probably found experimentally as they showed a low relative energy, and therefore need to be separated experimentally.

For these structures we have performed the optimizations at the DFT/B3LYP/6-31++G(d,p) level in order to compare their stabilities and check the accuracy of our results by using purely DFT calculations. We show in Fig. 3 the structures of Trans-1 and Trans-3 isomers optimized at DFT/B3LYP/6-31++G(d,p) level. 


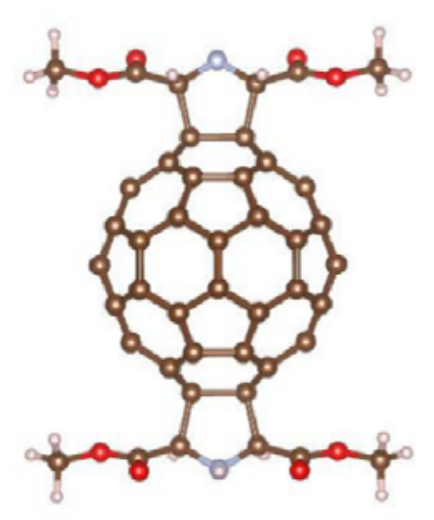

(a)

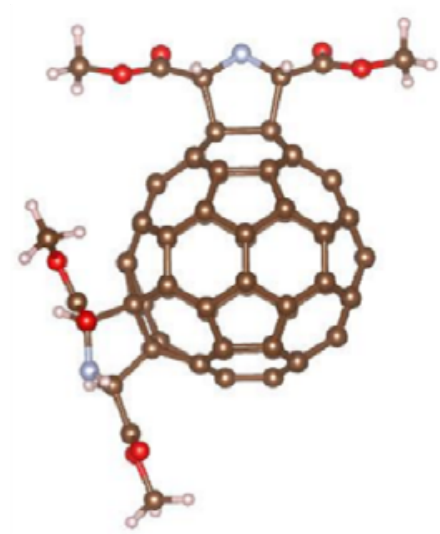

(b)

Fig. 3 - (a) Trans-1 and (b) Trans-3 fulleropyrrolidines isomers.

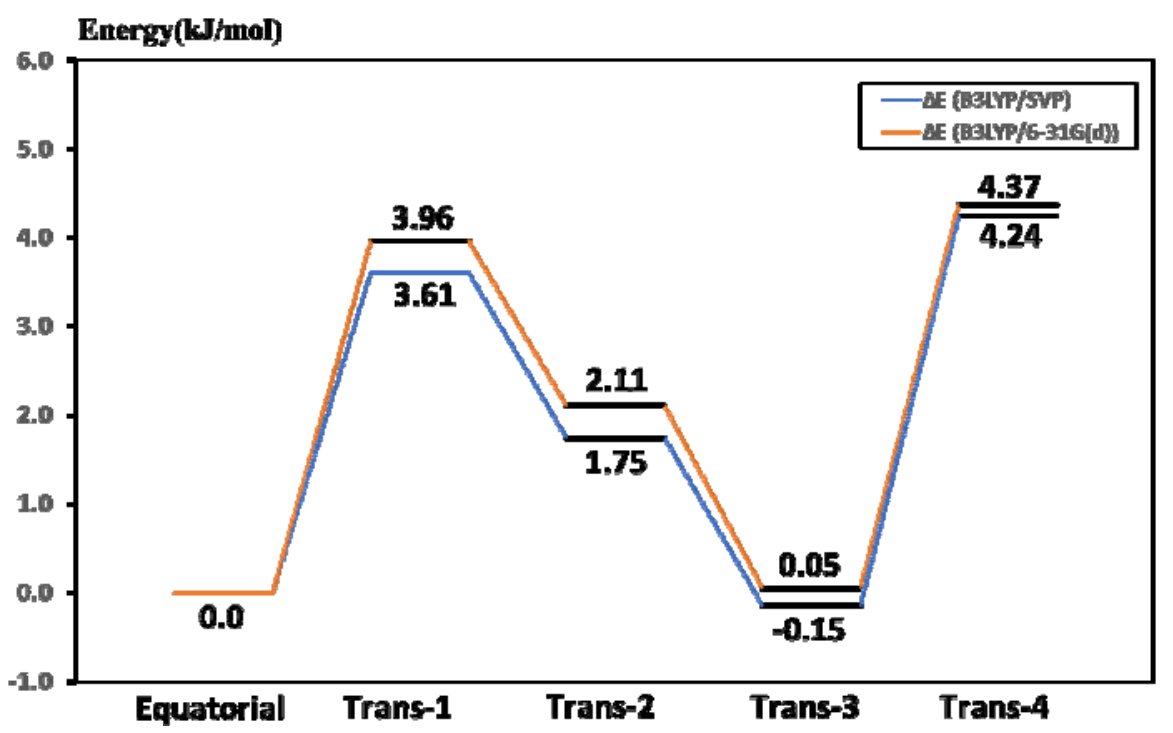

Fig. 4 - Different isomers and their corresponding relative energies in $\mathrm{kJ} / \mathrm{mol}$.

Table 2

Calculated HOMO, LUMO and energy gap for different molecules with B3LYP/6-31++G(d,p)

\begin{tabular}{c|c|c|c}
\hline Molecule & HOMO & LUMO & Band gap (eV) \\
\hline Fullerene $\mathrm{C}_{60}$ & -6.40 & -3.68 & 2.72 \\
Fulleropyrrolidines (mono-adduct) & -6.12 & -3.59 & 2.53 \\
Equa (bis-adduct) & -6.00 & -3.44 & 2.55 \\
Trans-1 (bis-adduct) & -5.95 & -3.51 & 2.43 \\
Trans-2 (bis-adduct) & -5.98 & -3.50 & 2.47 \\
Trans-3 (bis-adduct) & -5.95 & -3.43 & 2.52 \\
Trans-4 (bis-adduct) & -5.91 & -3.42 & 2.49 \\
\hline
\end{tabular}

All energies are presented in $\mathrm{eV}$.

DFT calculations B3LYP/6-31++G(d,p) show that Trans-3 isomer is considerably more stable than Trans-1 and Trans-4 isomers. It is more in competition with Equatorial isomer.
In Table 2, we report the LUMO and HOMO energies for the most important isomers of fulleropyrrolidines (Equatorial and Trans-3). These electrochemical properties are calculated at DFT 
level using the B3LYP functional and the 6$31++\mathrm{G}(\mathrm{d})$ basis set. When compared to the LUMO of the c60 alone and the mono adduct, the LUMO values of our studied bis-adduct fulleropyrrolidines confirm that these systems are able to increase the open circuit voltage of polymers in solar cells thanks to the high LUMO of the different isomers. These isomers can be considered as excellent electron acceptors.

If we use many Trans 1 isomers in the solar cell, these structures can form channels ${ }^{2}$ with $\pi-\pi$ interactions between them without restriction. Thus, the electron mobility property in this chain is significantly improved.

Other spectroscopic properties for Equa, Trans-1, Trans-2 and Trans-3 isomers are calculated in our work. We summarize in Table 3 the spectroscopic parameters calculated by B3LYP/SVP//6-31G(d) method. These results can help to clarify the mixtures of compounds with different number of adducts including the bis adducts. ${ }^{5}$

Table 3

UV-Vis spectroscopy. Optimization (B3LYP/SVP//6-31G(d))

\begin{tabular}{c|c|c|c|c|c}
\hline & Mono & Equa & Trans-1 & Trans-2 & Trans-3 \\
\hline$\lambda_{\text {cal }}(\mathbf{n m})$ & 648.78 & 634.49 & 686.34 & 667.91 & 651.97 \\
Excitation Energy (eV) & 1.91 & 1.95 & 1.81 & 1.86 & 1.90 \\
oscillator strength $(f)$ & 0.0018 & 0.0000 & 0.0000 & 0.0033 & 0.0013 \\
\hline \multicolumn{5}{|c|}{ HOMO - LUMO } \\
\hline
\end{tabular}

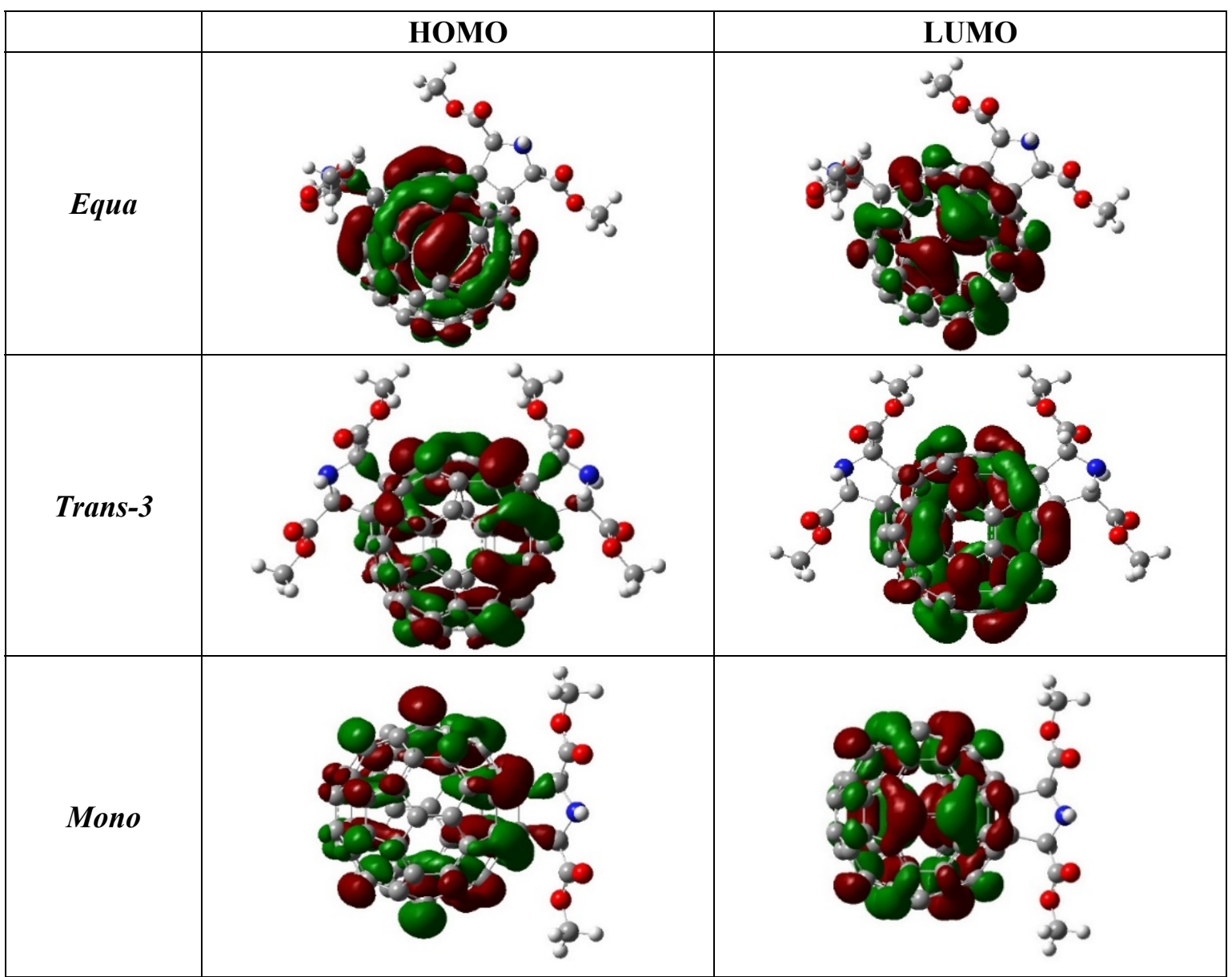

Fig. 5 - Isodensity plots (0.02 atomic units): HOMO (left column) and LUMO (right column) orbitals for Equa, Trans-3 and Cis-3 for bis-adduct fulleropyrrolidines isomer compared to mono-adduct fulleropyrrolidines at B3LYP/SVP//6-31G(d). 
Table 4

IR spectroscopy. Optimization (B3LYP/SVP//6-31G(d))

\begin{tabular}{c|c|c|c|c}
\hline \multirow{2}{*}{ Assignement } & \multicolumn{3}{|c}{ Modes } \\
\cline { 2 - 5 } & Clear fullerene & Mono-adduct & Bis-adduct (Equa) & Bis-adduct (Trans3) \\
\hline C-C & 1471 & $1470-1507$ & $1473-1504$ & $1469-1502$ \\
C-N & - & 1237 & 1237 & 1237 \\
C-O & - & 1036 & 1036 & 1036 \\
C-O & - & 1247 & 1247 & 1247 \\
C=O & - & 1850 & 1850 & 350 \\
C-H (sym) & - & 3050 & 3050 & 3050 \\
C-H (asym) & - & 3496 & 3141 & 3141 \\
N-H & - & & 3496 & 3496 \\
\hline
\end{tabular}

The different molecular orbitals for these structures are presented in Fig. 5. We notice that almost all the frontier orbitals are localized in the C60 system, and little contribution is found on the adsorbed molecules. These changes can be attributed to the change in the symmetry of the hole molecule and the formation of new bonds between the adduct and c60. Even if this contribution is small, results show that this is sufficient to make the bis adduct possess a higher LUMO energy than the mono adduct.

Table 4 presents the results of the most important vibrations of the clear fullerene, the mono-adduct, the bis adduct (Equa) and the Bisadduct (Trans-3). The vibrations of the complexes are different from the clear fullerene, however, the difference in vibrations for the compounds containing adducts are less obvious.

\section{CONCLUSIONS}

We performed a theoretical study of the different possible isomers of bis-adduct fulleropyrrolidines. We optimized the structures and calculated the corresponding equilibrium energies and the structural properties. Our calculations showed that Equa and Trans-3 isomers are the most stable among the eight possible isomers. Density functional theory method (B3LYP/6-31++G(d,p)) confirmed the order of the most favorable isomers. We also found that the LUMO of bis-adducts (Equa and Trans isomers) are higher than the $\mathrm{C}_{60}$ and the mono-adduct. These bi adducts are promising electron acceptors because of their ability to increase the open circuit voltage of the polymers of solar cells thanks to their high LUMO.
Acknowledgements. The authors acknowledge Dr. Mhamed BEN MESSAOUDA, University of Manouba for calculation resources and computer time. Dr. Abdesslem Jedidi is grateful to the KAUST Supercomputing Laboratory (Shaheen II) and High-Performance Computing Center (Aziz Supercomputer) at King Abdulaziz University (KAU) for the resources and the support.

\section{REFERENCES}

1. H. W. Kroto, J. R. Heath, S. C. O'Brien, R. F. Curl and R. E. Smalley, Nature, 1985, 318,162.

2. X. Meng, G. Zhao, Q. Xu, Z. A. Tan, Z. Zhang, L. Jiang, C. Shu, C. Wang and Y. Li, Advanced Funct. Mater., 2014, 24,158.

3. P. Pitliya, Y. Sun, J. C. Garza, C. Liu, X. Gong, A. Karim and D. Raghavan, Polymer, 2014, 55, 1769.

4. Q. Lu, D. I. Schuster and S. R. Wilson, J. Org. Chem., 1996, 61, 4764.

5. M. de Person, A. Coffre, R. Skanji, M. Ben Messaouda, M. Abderraba, Y. Zhang and F. Moussa, Tetrahedron, 2013, 69, 6826 .

6. S. H. Lim, D. W. Cho, J. Choi, H. An, J. H. Shim and P. S. Mariano, Tetrahedron, 2017, 73, 6249.

7. R. Skanji, M. Ben Messaouda, Y. Zhang, M. Abderrabba, H. Szwarc and F. Moussa, Tetrahedron, 2012, 68, 2713.

8. A. Artigas, A. Lledó, A. Pla-Quintana, A. Roglans and M. Solà, Chem. - Eur. J., 2017, 23, 15067.

9. S. Bennia, R. Milad, S. Messaoudi, M. de Person, F. Moussa, M. Abderrabba and D. Merlet, PLOS ONE, 2018, 13, e0207635.

10. N. Khemiri, S. Messaoudi, F. Moussa, M. Abderrabba and H. Chermette, Theo. Chem. Acc., 2016, 135, 265.

11. K. Kordatos, S. Bosi, T. Da Ros, A. Zambon, V. Lucchini and M. Prato, J. Org. Chem., 2001, 66, 2802.

12. A. D. Boese and G. E. Scuseria, Chem. Phys. Lett., 1998, 294, 233.

13. C. Lee, W. Yang and R. G. Parr, Phys. Review B, 1988, 37,785 .

14. B. Werghi, A. Bendjeriou-Sedjerari, A. Jedidi, E. AbouHamad, L. Cavallo and J.-M. Basset, Organometallics, 2016, 35, 3288.

15. M. J. Frisch, G. W. Trucks, H. B. Schlegel, G. E. Scuseria, M. A. Robb, J. R. Cheeseman, G. Scalmani, V. 
Barone, B. Mennucci, G. A. Petersson, H. Nakatsuji, M. Caricato, X. Li, H. P. Hratchian, A. F. Izmaylov, J. Bloino, G. Zheng, J. L. Sonnenberg, M. Hada, M. Ehara, K. Toyota, R. Fukuda, J. Hasegawa, M. Ishida, T. Nakajima, Y. Honda, O. Kitao, H. Nakai, T. Vreven, J. A. Montgomery Jr., J. E. Peralta, F. Ogliaro, M. J. Bearpark, J. Heyd, E. N. Brothers, K. N. Kudin, V. N. Staroverov, R. Kobayashi, J. Normand, K. Raghavachari, A. P. Rendell, J. C. Burant, S. S. Iyengar, J. Tomasi, M. Cossi, N. Rega, N. J. Millam, M. Klene, J. E. Knox, J. B. Cross, V. Bakken, C. Adamo, J. Jaramillo, R. Gomperts, R.E. Stratmann, O. Yazyev, A. J. Austin, R. Cammi, C.
Pomelli, J. W. Ochterski, R. L. Martin, K. Morokuma, V. G. Zakrzewski, G. A. Voth, P. Salvador, J. J. Dannenberg, S. Dapprich, A. D. Daniels, Ö. Farkas, J. B. Foresman, J. V. Ortiz, J. Cioslowski, D. J. Fox, Gaussian 09. Gaussian, Inc., Wallingford, CT, USA, 2009.

16. A. D. Becke, J. Chem. Phys., 1993, 98, 5648.

17. G. Yang, Y. Si and Z. Su, J. Phys. Chem. A, 2011, 115, 13356.

18. S. G. Aziz, O. I. Osman, S. A. Elroby, W. M. I. Hassan, A. Jedidi and R. H. Hilal, Struct. Chem., 2018, $29,1$.

19. A. Hirsch, I. Lamparth and H. R. Karfunkel, Angewandte Chemie International (Edition in English), 1994, 33, 437. 
